\begin{tabular}{|c|c|}
\hline Title & Molecular motion in pyridazinium/crown ether supramolecular cation salts of a nickel dithiolene complex \\
\hline Author(s) & $\begin{array}{l}\text { Liu, Zun-qi; Kubo, Kazuya; Lin, Li; Hoshino, Norihisa; Noro, Shin-ichiro; A kutagawa, Tomoyuki; Nakamura, } \\
\text { T akay oshi }\end{array}$ \\
\hline Citation & $\begin{array}{l}\text { Dalton Transactions, 42(8), 2930-2939 } \\
\text { https://doi.org/10.1039/c2dt32542j }\end{array}$ \\
\hline Issue Date & $2013-02-28$ \\
\hline Doc URL & http:/hdl.handle.net/2115/53693 \\
\hline Rights & Dalton Trans., 2013,42, 2930-2939- Reproduced by permission of The Royal Society of Chemistry (RSC) \\
\hline Tyре & article (author version) \\
\hline File Information & DT42-8_2930-2939.pdf \\
\hline
\end{tabular}

Instructions for use 


\title{
Molecular Motion in Pyridazinium/Crown Ether Supramolecular Cation Salts of a Nickel Dithiolene Complex
}

\author{
Zun-qi Liu, ${ }^{a}$ Kazuya Kubo, ${ }^{* a, b}$ Li Lin, ${ }^{a}$ Norihisa Hoshino, ${ }^{c}$ Shin-ichiro Noro, ${ }^{a, b}$ Tomoyuki Akutagawa, \\ Takayoshi Nakamura*a,b
}

\author{
s Received (in $X X X, X X X)$ Xth $X X X X X X X X X 20 X X$, Accepted Xth XXXXXXXXX 20XX \\ DOI: $10.1039 / b 000000 x$
}

Supramolecular cations formed by monoprotonated pyridazinium cations and cis-anti-cis-

dicyclohexano[18]-crown-6 (DCH[18]-crown-6) or dibenzo[18]-crown-6 (DB[18]-crown-6) were

introduced into $\left[\mathrm{Ni}(\mathrm{dmit})_{2}\right]^{-}$salts (where $\mathrm{dmit}^{2-}=2$-thione-1,3-dithiole-4,5-dithiolate). X-ray crystal

10 structure analysis of $\left(\right.$ pyridazinium $\left.{ }^{+}\right)\left(\mathrm{DCH}[18]\right.$-crown-6) $\left[\mathrm{Ni}\left(\mathrm{dmit}_{2}\right]^{-}(\mathbf{1})\right.$ revealed a chair-type

conformation of the DCH[18]-crown-6 moiety. A V-shaped conformation of the DB[18]-crown-6 moiety

was observed in (pyridazinium $\left.{ }^{+}\right)(\mathrm{DB}[18] \text {-crown-6 })_{2}\left[\mathrm{Ni}\left(\mathrm{dmit}_{2}\right]^{-}\left(\mathrm{H}_{2} \mathrm{O}\right)_{2}(\mathbf{2})\right.$. Nitrogen atoms in the

pyridazinium cations interacted with the oxygen atoms of the DCH[18]-crown-6 and DB[18]-crown-6

through $\mathrm{N}-\mathrm{H}^{+} \sim \mathrm{O}$ hydrogen bonds, forming 1:1 and 1:2 supramolecular structures, respectively. Sufficient

15 space for molecular motions of the pyridazinium cations, namely flip-flop and in-plane rotations, exists in salt 1. Disorder in nitrogen atoms was observed by $\mathrm{X}$-ray analysis, indicating dynamic motion of the pyridazinium cation, namely flip-flop motion and in-plane motion. A potential energy calculation further supported the possibility of dynamic motion of cations in the crystal. By contrast, the flip-flop motion of the pyridazinium group in salt $\mathbf{2}$ is restricted by the two nearest-neighbouring DB[18]-crown-6 molecules.

${ }_{20}$ Weak antiferromagnetic intermolecular interactions between the $\left[\mathrm{Ni}(\mathrm{dmit})_{2}\right]^{-}$anions in the two-

dimensional layers of salt $\mathbf{1}$ were observed, resulting in alternating antiferromagnetic Heisenberg chain-

type magnetic susceptibility. Quasi-one-dimensional intermolecular interactions between the $\left[\mathrm{Ni}(\mathrm{dmit})_{2}\right]$

anions were observed in salt $\mathbf{2}$, whose magnetic behaviour followed the Bonner-Fisher model.

\section{Introduction}

25 Development of artificial molecular rotators has attracted attention in recent years. ${ }^{1}$ Living organisms have high efficient energy conversion systems that use molecular rotation. For example, the transport of protons through mitochondrial membranes causes the rotation of ATPase; that is, a $360^{\circ}$ rotation 30 of ATPase is achieved by the passage of three protons, resulting in the production of one ATP from ADP. ${ }^{2}$ Biological systems are excellent models of highly efficient energy conversion systems. However, it is difficult to develop artificial systems from living organisms because of the complexity of protein structures and 35 chemical instabilities in the biological system. Besides the energy conversion, the development of artificial molecular systems that exhibit molecular rotation, even unidirectional molecular rotation, has been extensively studied in recent years. ${ }^{3,4}$ For example, Hiraoka et al. reported a sandwich-type trinuclear silver(I) 40 complex formed by coordination bonds between silver ions and sulfur and/or nitrogen atoms in planar ligands. The complex can act like a molecular bearing in the solution because of the difference in coordination ability between the silver ion and the heteroatoms. ${ }^{5}$ Muraoka et al. designed a molecular pincer based 45 on a ferrocene moiety with an azobenzene strap, each end of which is attached to one of the two cyclopentadienyl rings of the ferrocene unit. The ferrocene moiety acted as a pivot, and cistrans photoisomerization of the strap caused the rotation of the cyclopentadienyl rings by changing the relative position of two 50 "pedal" moieties attached to the ferrocene rings. ${ }^{6}$ Unidirectional rotary motion was realized by using a triptycene derivative with a [4]helicene moiety. The unidirectional rotation of the molecule in solution was achieved through two-step photochemical reactions, each of which was followed by thermal rearrangement of the 55 molecule. $^{7}$ Catenanes also are good candidates for achieving unidirectional rotation. Leigh et al. showed unidirectional molecular rotation in a [3]catenane driven by light, heat or chemical stimuli. ${ }^{4}$ A number of molecular rotators in solution have been reported. However, there have been few reports of 60 molecular machines in the solid state. The development of molecular gyroscope systems was a pioneering work in the field of solid-state molecular machines. Molecular gyroscopes or compass systems based on bis(triarylmethyl) frame or triptycene moieties in the solid state have been reported. ${ }^{8}$

${ }_{65}$ We have reported molecular rotators based on supramolecules formed by crown ether and anilinium derivatives through hydrogen bonding, which showed a random rotation within the crystal through thermal fluctuation. ${ }^{9-12}$ For example, a supramolecular cation $\left(\right.$ anilinium $\left.^{+}\right)([18]$-crown-6) within the 
crystal of $\left(\right.$ anilinium $\left.^{+}\right)([18]-$ crown- 6$)\left[\mathrm{Ni}(\mathrm{dmit})_{2}\right]^{-}$showed a flipflop molecular motion of the phenyl ring around a two-fold axis along the $\mathrm{C}-\mathrm{N}$ bond at $3 \mathrm{MHz}$ at room temperature. ${ }^{10}$ Molecular rotation of [18]-crown-6 was also observed in the same crystal. A 5 supramolecular cation of ( $m$-fluoroanilinium $\left.{ }^{+}\right)(\mathrm{DB}[18]$-crown-6) (DB[18]-crown-6 = dibenzo[18]-crown-6) in the crystal of $(m-$ fluoroanilinium $\left.\left.{ }^{+}\right)(\mathrm{DB}[18] \text {-crown-6)[Ni(dmit })_{2}\right]^{-}$showed flip-flop molecular motion, causing an inversion of the dipole moment due to the fluorine atom at the meta position. As a result, the crystal 10 exhibited an order-disorder type of ferroelectric transition at 348 $\mathrm{K}^{11}$

For molecular rotation within a crystal, it is essential to provide enough space for molecular rotators to reduce their rotational potential; utilization of smaller rotators is one of the preferable 15 designs. Supramolecular cations based on anilinium derivatives have a substituent on the aromatic rings that introduces a dipole moment. However, the substituents often cause a large energy barrier for their rotations because of steric hindrance. In this study, we adopted a monoprotonated pyridazinium cation whose 20 dipole moment is parallel to the ring surface, which originates from the two nitrogen atoms in the ring. The small size and the absence of substituents are expected to be advantageous for reducing the energy barriers to rotation, and to provide larger degrees of freedom for molecular motions within the crystal 25 (Scheme 1). Moreover, pyridazinium cations are expected to exhibit not only the flip-flop motion, but also in-plane molecular rotation and proton transfer. It is known that protonated cations of six-membered heteroaromatic rings can form supramolecular structures with crown ethers. ${ }^{13}$ By complexing monoprotonated 30 pyridazinium cations with [18]-crown-6, the $\mathrm{N}-\mathrm{H}^{+}$part will interact with the oxygen atoms in [18]-crown-6 through hydrogen bonding, forming a supramolecular rotator structure. The pyridazinium cation may exhibit flip-flop motion across the rotational axis along the hydrogen bond. In addition, in-phase 35 molecular rotation should be possible, given that the energy of hydrogen bonds is comparable to the thermal energy. In both cases, a large polarization change is expected because of the change in direction of the dipole moment in the crystal. Moreover, intra- and intermolecular proton transfer may cause the inversion 40 of the dipole-moment direction in the crystal.<smiles>C1CC[C@H]2OCCOCCO[C@H]3CCCC[C@H]3OCCOCCO[C@H]2C1</smiles>

45 DCH[18]crown-6<smiles>S=c1sc2c(s1)S[N+]1(S2)Sc2sc(=S)sc2S1</smiles><smiles>c1ccc2c(c1)OCCOCCOc1ccccc1OCCOCCO2</smiles>

DB[18]crown-6<smiles></smiles>
pyridazinium $^{+}$
Scheme 1 Components of the salts.

In this paper, $\left[\mathrm{Ni}(\mathrm{dmit})_{2}\right]^{-}$salts with supramolecular cations based on pyridazinium, (pyridazinium $\left.{ }^{+}\right)\left(\mathrm{DCH}[18]\right.$-crown-6) $\left[\mathrm{Ni}(\mathrm{dmit})_{2}\right]^{-}$ (1) $(\mathrm{DCH}[18]$-crown-6 = cis-anti-cis-dicyclohexano[18]-crown$\left.{ }_{55} 6\right)$ and (pyridazinium $\left.{ }^{+}\right)(\mathrm{DB}[18] \text {-crown-6) })_{2}\left[\mathrm{Ni}(\mathrm{dmit})_{2}\right]\left(\mathrm{H}_{2} \mathrm{O}\right)_{2}(2)$, were used. The molecular rotations are discussed in terms of $\mathrm{X}$ ray crystallographic analyses and rotational energy potential calculations.

\section{Experimental}

\section{Materials.}

The dicyclohexano[18]-crown-6 was purchased from Wako Pure Chemical Industries, Ltd. as a 1:1 mixture of cis-syn-cis and cisanti-cis isomers, which was directly used without further purification. (pyridazinium $\left.{ }^{+}\right)\left(\mathrm{BF}_{4}^{-}\right)$was prepared using a similar ${ }_{65}$ procedure to that described in the literature. ${ }^{9-12}$

\section{General.}

Elemental analyses and IR (400-7800 $\left.\mathrm{cm}^{-1}\right)$ spectra were measured using a YANACO CHN CORDER MT-6a and a Thermo Scientific Nicolet 6700 FT-IR, respectively.

\section{${ }_{70}$ Preparation of (pyridazinium $\left.{ }^{+}\right)(\mathrm{DCH}[18]-c r o w n-$ 6) $\left[\mathrm{Ni}\left(\text { dmit }_{2}\right]^{-}\right.$(1) and (pyridazinium $\left.{ }^{+}\right)(\mathrm{DB}[18]$-crown- 6) $)_{2}\left[\mathrm{Ni}(\mathrm{dmit})_{2}\right]^{-}\left(\mathrm{H}_{2} \mathrm{O}\right)_{2}(2)$.}

An acetone solution $(20 \mathrm{ml})$ of $\left(n-\mathrm{Bu}_{4} \mathrm{~N}^{+}\right)\left[\mathrm{Ni}(\mathrm{dmit})_{2}\right]^{-}(20 \mathrm{mg}$, $0.028 \mathrm{mmol})^{14}$ was added to an acetone solution $(20 \mathrm{ml})$ of 75 (pyridazinium $\left.^{+}\right)\left(\mathrm{BF}_{4}^{-}\right)(50 \mathrm{mg}, 300 \mathrm{mmol})$ and $\mathrm{DCH}[18]$-crown-6 (200 mg, $540 \mathrm{mmol}$ ). The solvent was evaporated for one week at room temperature to give crystal $\mathbf{1}$ as a black block crystal. Crystal 2 was obtained as a black block crystal using a similar method. The compositions of the salts were determined by 80 elemental and $\mathrm{X}$-ray crystallographic analyses. Anal. $\mathrm{C}_{30} \mathrm{H}_{41} \mathrm{~N}_{2} \mathrm{O}_{6} \mathrm{~S}_{10} \mathrm{Ni}$ for salt 1; Calcd, C: $39.81, \mathrm{H}: 4.57, \mathrm{~N}: 3.11 \%$; Found, C: 39.78, H: 4.51, N: 3.11\%. Anal. $\mathrm{C}_{50} \mathrm{H}_{57} \mathrm{~N}_{2} \mathrm{O}_{14} \mathrm{~S}_{10} \mathrm{Ni}$ for salt 2; Calcd, C: 46.54, H: 4.46, N: 2.17\%; Found: C: 46.61, $\mathrm{H}: 4.38, \mathrm{~N}: 2.17 \%$.

\section{${ }_{85}$ Crystal structure determination.}

Crystallographic data of the single crystals $\mathbf{1}$ and $\mathbf{2}$ were collected using a Rigaku R-AXIS RAPID diffractometer with MoK $\alpha$ radiation $(\lambda=0.71075 \AA$ ) from a graphite monochromator at 93 and $300 \mathrm{~K}$. The structures were solved by the direct method (SIR ${ }_{90} 2004$ ) and expanded using Fourier techniques and refined on $F^{2}$ by the full-matrix least-squares method (SHELXL97) compiled into Yadokari-XG. ${ }^{15}$ The parameters were refined using anisotropic temperature factors, except for the hydrogen atoms, which were refined using the riding model with a fixed $\mathrm{C}-\mathrm{H}$ bond 95 distance of $0.95 \AA$. The crystallographic data of salts $\mathbf{1}$ and $\mathbf{2}$ at 93 are summarized in Table 1 . The data for $300 \mathrm{~K}$ appear to be given in Table S1. The position of one nitrogen atom in the pyridazinium cations of each salt was determined from the distances between the nitrogen and oxygen atoms in the crown 100 ethers. The position of a second nitrogen atom in the pyridazinium cation could not be determined because of the similar electron densities of carbon and nitrogen atoms. The nitrogen atoms without hydrogen bonds were solved as carbon atoms. The hydrogen atoms in the pyridazinium cations were not 105 calculated because of the disorder of the cations. 
Table 1. Crystallographic data of salts 1 and 2 at $93 \mathrm{~K}$.

\begin{tabular}{|c|c|c|}
\hline & 1 & 2 \\
\hline Chemical formula & $\mathrm{C}_{31} \mathrm{H}_{37} \mathrm{NNiO}_{6} \mathrm{~S}_{10}$ & $\mathrm{C}_{51} \mathrm{H}_{53} \mathrm{NNiO}_{14} \mathrm{~S}_{10}$ \\
\hline Formula weight & 897.92 & 1278.21 \\
\hline Temperature (K) & 93 & 93 \\
\hline Crystal size $\left(\mathrm{mm}^{3}\right)$ & $0.20 \times 0.20 \times 0.04$ & $0.20 \times 0.20 \times 0.20$ \\
\hline Crystal system & Triclinic & Triclinic \\
\hline Space group & $P-1$ & $P-1$ \\
\hline$a(\AA)$ & $12.3282(7)$ & $10.1033(3)$ \\
\hline$b(\AA)$ & $13.1671(8)$ & $15.7356(7)$ \\
\hline$c(\AA)$ & $13.5519(7)$ & $17.8817(6)$ \\
\hline$\alpha\left(^{\circ}\right)$ & $67.4445(18)$ & $86.1276(16)$ \\
\hline$\beta\left(^{\circ}\right)$ & $81.0005(16)$ & $83.8303(10)$ \\
\hline$\gamma\left({ }^{\circ}\right)$ & $77.229(2)$ & $89.2463(15)$ \\
\hline$V\left(\AA^{3}\right)$ & 1975.03(19) & 2819.89(18) \\
\hline$Z$ & 2 & 2 \\
\hline$D_{\text {calc }}\left(\mathrm{g} \cdot \mathrm{cm}^{-1}\right)$ & 1.510 & 1.505 \\
\hline$F(000)$ & 930 & 1322 \\
\hline$\mu\left(\mathrm{mm}^{-1}\right)$ & 1.062 & 0.779 \\
\hline Measured $2 \theta$ range $\left(^{\circ}\right)$ & $6.2-55.0$ & $6.2-55.0$ \\
\hline $\begin{array}{l}\text { No. of reflections } \\
\text { collected }\end{array}$ & 19188 & 27968 \\
\hline Independent reflections & 8886 & 12866 \\
\hline $\begin{array}{l}\text { Observed reflections } \\
\text { with } I>2.00 s(I)\end{array}$ & 7312 & 11769 \\
\hline$R_{\text {int }}$ & 0.0308 & 0.0304 \\
\hline$R(I>2 \sigma(I))^{[\mathrm{a}]}$ & 0.0436 & 0.0408 \\
\hline${ }_{\mathrm{w}} R(\text { all data })^{[\mathrm{b}]}$ & 0.1148 & 0.1126 \\
\hline GOF & 1.068 & 1.036 \\
\hline \multicolumn{3}{|c|}{$\begin{array}{c}{ }^{[\mathrm{a}]} R=\Sigma\left(\left|F_{\mathrm{o}}\right|-\left|F_{\mathrm{c}}\right|\right) / \Sigma\left|F_{\mathrm{o}}\right| \cdot{ }^{[\mathrm{b}]}{ }_{w} R^{2}=\Sigma_{w}\left(F_{\mathrm{o}}{ }^{2}-{F_{\mathrm{c}}}^{2}\right)^{2} / \Sigma_{w}\left(F_{\mathrm{o}}{ }^{2}\right)^{2} ; w^{-1}=\sigma^{2}\left(F_{\mathrm{o}}{ }^{2}\right)- \\
(0.0624 P)^{2}-1.9422 P \text { for } 1 w^{-1}=\sigma^{2}\left(F_{\mathrm{o}}{ }^{2}\right)-(0.0621 P)^{2}-2.4445 P \text { for 2, } \\
\text { where } P=\left(F_{\mathrm{o}}{ }^{2}-2 F_{\mathrm{c}}{ }^{2}\right) / 3 .\end{array}$} \\
\hline
\end{tabular}

\section{Magnetic susceptibility.}

Temperature-dependent magnetic susceptibilities of salts $\mathbf{1}$ and $\mathbf{2}$ were measured using a Quantum Design MPMS-XL SQUID magnetometer for the polycrystalline samples. The DC magnetic susceptibility was measured at temperatures from 2 to $300 \mathrm{~K}$ in 10 an applied field of $1 \mathrm{~T}$.

\section{Calculations.}

The relative energy of the structures was calculated by a semiempirical method using the RHF/6-31(d) basis set. ${ }^{16}$ The nearest-neighboring molecules around the $\mathrm{N}-\mathrm{H}$ bonds of 15 pyridazinium were included in the calculation of the potential energy curve. The structural units of the salts used in the calculations were (pyridazinium $\left.^{+}\right)(\mathrm{DCH}[18]-\text { crown-6) })_{2}$ and ${\left(\text { pyridazinium }^{+}\right)(\mathrm{DB}[18]-\text { crown-6) }}_{2}$, respectively, which are different from the real stoichiometry of the salts (Figure S1). The 20 atomic coordinates of the salts based on the X-ray crystal structural analyses were used in the calculations. The relative energies of the structures were obtained by evaluating the rigid rotation around the $\mathrm{C}(4)-\mathrm{N}(1)$ axes for the flip-flop motion. Rotations were performed in $30^{\circ}$ steps, and the relative energies 25 were calculated using fixed atomic coordinates. The relative energies for in-plane rotations of the cations in salts $\mathbf{1}$ and $\mathbf{2}$ were calculated using the same structural units as those used in the flip-flop motion calculations. Rotations were performed in $10^{\circ}$ steps, and the relative energies were calculated using fixed atomic 30 coordinates.

The overlap integrals $(s)$ between the lowest unoccupied molecular orbitals (LUMOs) of the $\left[\mathrm{Ni}(\mathrm{dmit})_{2}\right]^{-}$anions were calculated by a tight-binding approximation using an extended Hückel method. Semiempirical parameters for the Slater-type 35 atomic orbitals were obtained from the literature. ${ }^{17}$ Transfer integrals $(t)$ were obtained by the equation $t=-10 \mathrm{~s}$.

\section{Results and discussion}

\section{Crystal Structure of $\left(\right.$ pyridazinium $\left.^{+}\right)(\mathrm{DCH}[18]$-crown- 6) $\left[\mathrm{Ni}(\mathrm{dmit})_{2}\right]^{-}$(1).}

40 The crystal structure of salt $\mathbf{1}$ at $93 \mathrm{~K}$ is shown in Figure 1. In salt 1, one DCH[18]-crown-6, one pyridazinium cation, and one $\left[\mathrm{Ni}(\mathrm{dmit})_{2}\right]^{-}$molecule form the asymmetric unit. The cationic and anionic layers alternate along the $b+c$ axis (Figure 1(b)). The crown ether and pyridazinium are alternately stacked along the $a$ 45 axis, forming one-dimensional columns (Figure 1(c)). Although the anisotropic thermal factors of the atoms in the pyridazinium cation were larger at $300 \mathrm{~K}$ than at $93 \mathrm{~K}$, no significant change was observed between the crystal structures at 93 and $300 \mathrm{~K}$ (see Supporting Information). Figure 2(a) depicts the supramolecular 50 structure of the pyridazinium cation and DCH[18]-crown-6. The DCH[18]-crown-6 had cis-anti-cis configuration. The positions of the nitrogen atoms in the pyridazinium cation were determined from the distance between the nitrogen atom and the six oxygen atoms in $\mathrm{DCH}[18]$-crown-6. The distance $\mathrm{N}(1)-\mathrm{O}(1)$ was 2.892 $55 \AA$, which was the shortest of the nitrogen-oxygen interatomic distances $(2.892-4.640 \AA)$. The hydrogen bond should form at this position, $\mathrm{N}(1)-\mathrm{H}^{+} \sim \mathrm{O}(1)$. The positions of neighboring nitrogen atoms in the pyridazinium cation cannot be determined because of the similar electron densities of nitrogen and carbon 60 atoms. In this crystal structure analysis, another nitrogen atom in the pyridazinium cation were solved as carbon atoms. The shortest distances between the oxygen atoms of DCH[18]-crown6 and the carbon atoms next to nitrogen atoms were $3.050(\mathrm{C}(1)$ $\mathrm{O}(3))$ and $3.554(\mathrm{C}(5)-\mathrm{O}(1)) \AA$. The bond angles $\mathrm{C}(1)-\mathrm{H} \cdots \mathrm{O}(3)$ ${ }_{65}$ and $\mathrm{C}(5)-\mathrm{H} \cdots \mathrm{O}(1)$ were 130.87 and $93.44^{\circ}$ respectively, obtained by the calculations for the addition of hydrogen atoms to the pyridazinium cation. Judging from the distances and the bond angles, a hydrogen bond at $\mathrm{C}(1)-\mathrm{O}(3)$ may be formed, which can be categorized as either a "moderate" or a "weak" hydrogen bond 70 by Jeffrey's classification. ${ }^{18}$ The energies of the hydrogen bonds should be less than about $20 \mathrm{~kJ} \mathrm{~mol}^{-1}$, slightly larger than the thermal energy. Thus, it is highly possible that the neighboring nitrogen atom was positioned randomly at the $\mathrm{C}(1)$ or the $\mathrm{C}(5)$ site in the pyridazinium cation, because of the orientational 75 disorder of pyridazinium cation caused by flip-flop motion. This phenomenon agrees well with the results of potential energy calculation for the flip-flop motion of the pyridazinium cation of the salt (see the next section). The distance between $C(3)$ and $\mathrm{O}$ (4) was $2.915 \AA$. A disordered pyridazinium cation can form a 80 weak hydrogen bond with another DCH[18]-crown-6 at this position. Scheme 2 is a schematic drawing of the orientational disorder of the pyridazinium cation in this crystal. The results suggest that not only flip-flop motion but also in-plane rotation of the pyridazinium cation can occur in the crystal. The distances of ${ }_{85} \mathrm{~N}(1)-\mathrm{C}\left(1^{* *}\right)$ and $\mathrm{C}(3)-\mathrm{C}\left(4^{* * *}\right)$, where the atoms $\mathrm{C}\left(1^{* *}\right)$ and $\mathrm{C}(4 * * *)$ were on neighboring pyridazinium cations, were 4.111 and $4.075 \AA$, respectively. The symmetry operations of $\mathrm{C}\left(1^{* *}\right)$ and $\mathrm{C}(4 * * *)$ were $(1+x, y, z)$ and $(-1+x, y, z)$. These distances are longer than typical hydrogen bonds between nitrogen atoms, 
indicating that proton transfers in this solid were difficult.

(a)

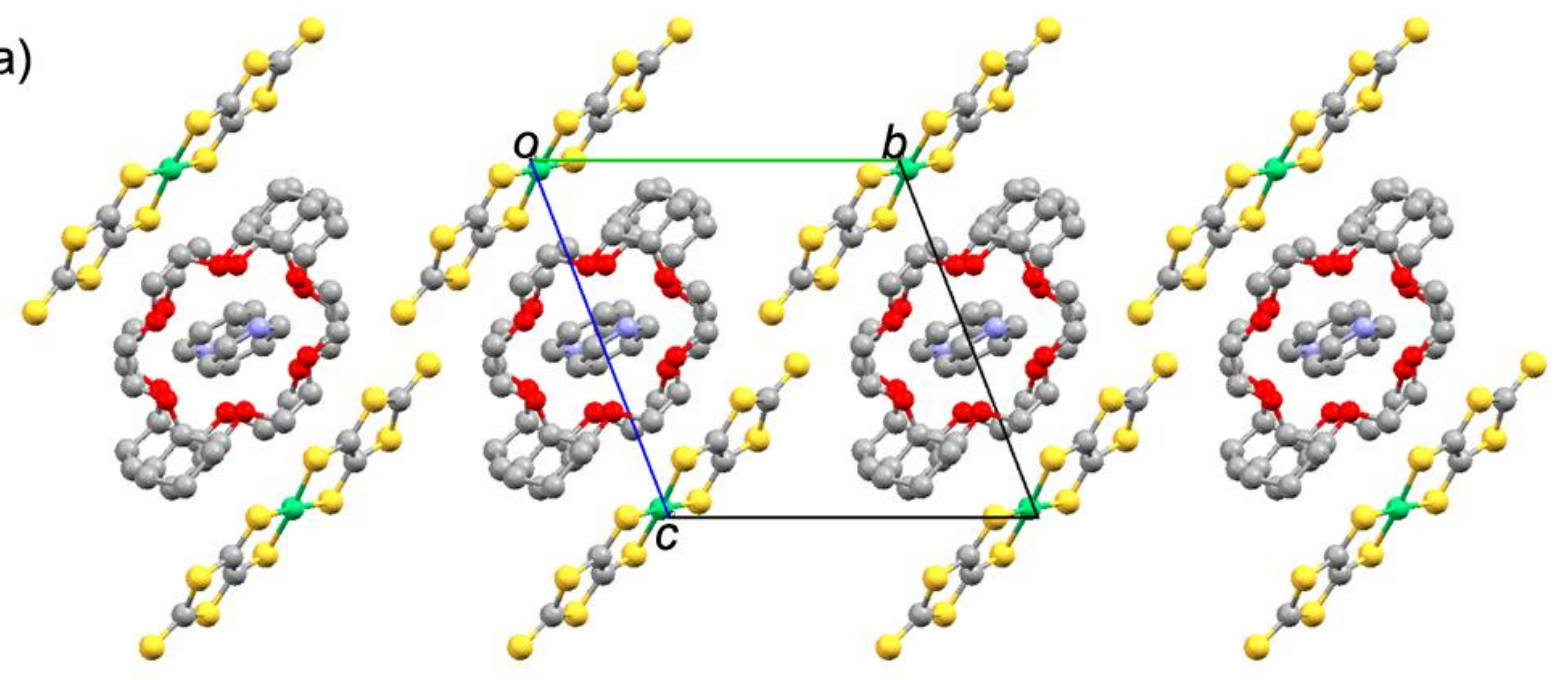

(b)

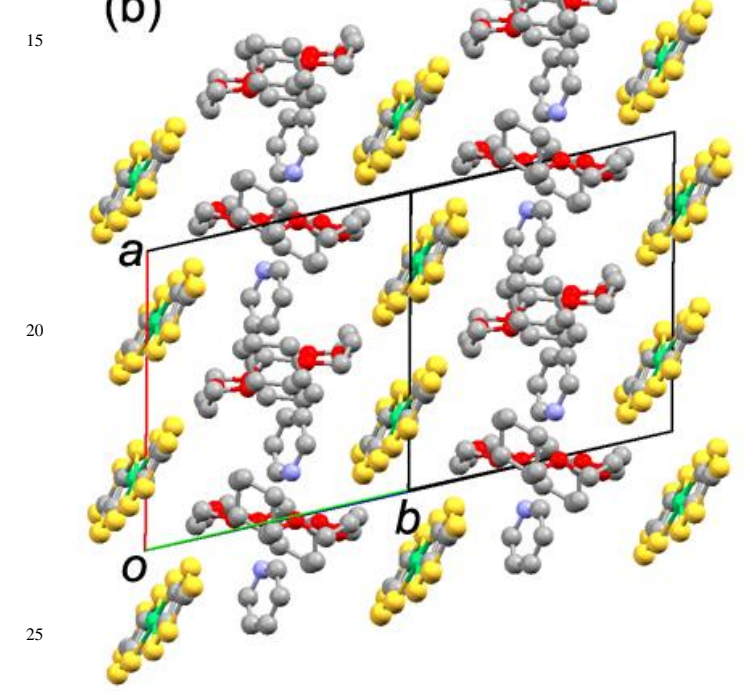

(c)

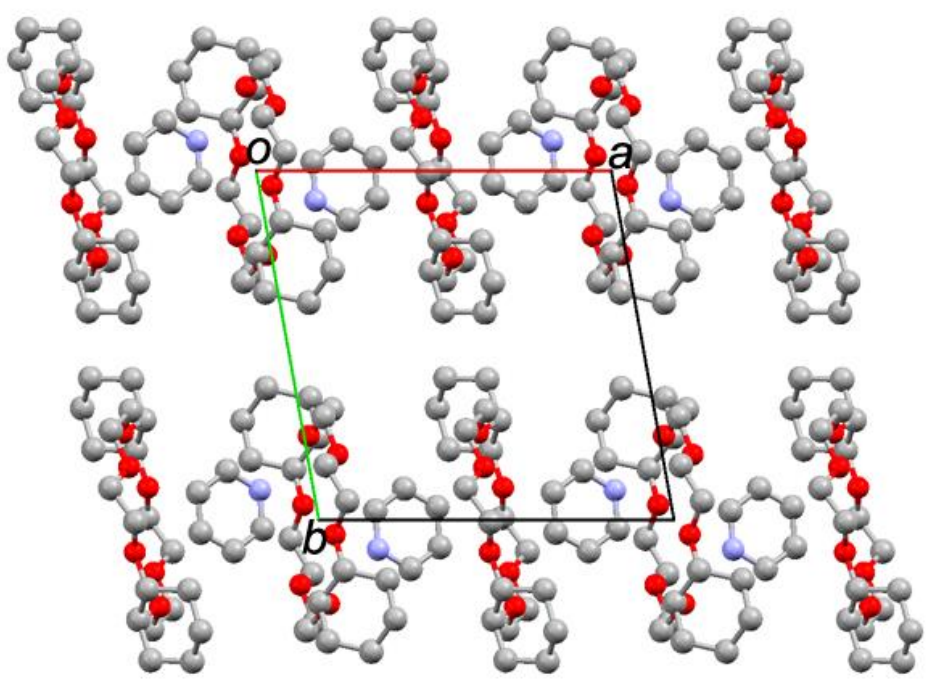

Fig. 1 Packing diagrams of salt 1 along (a) the $a$ axis and (b) the $b+c$ direction at $93 \mathrm{~K}$. (c) Molecular arrangement of the supramolecules. Hydrogen atoms have been omitted for clarity.

30

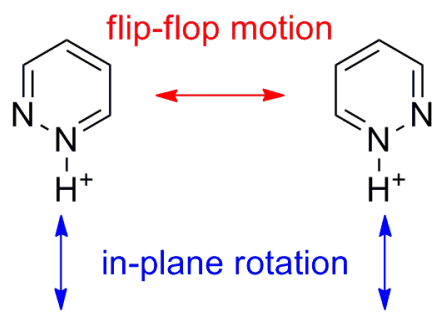

35<smiles></smiles>

Scheme 2 Schematic drawing of the orientational disorder of the pyridazinium cation in crystal $\mathbf{1}$.
${ }_{40}$ The $\left[\mathrm{Ni}(\mathrm{dmit})_{2}\right]^{-}$assembly in crystal $\mathbf{1}$ is shown in Figure 3 . The $\left[\mathrm{Ni}(\mathrm{dmit})_{2}\right]^{-}$molecule interacted via lateral sulfur-sulfur contacts along the $a$ axis, forming a one-dimensional chain. The distances between the sulfur atoms, $d_{1}-d_{4}$, were $3.733,3.971,3.846$, and $4.007 \AA$, respectively, which are slightly longer than the van der ${ }_{45}$ Waals radii of the sulfur atoms $(<3.70 \AA)$. The transfer integrals between the LUMOs of the $\left[\mathrm{Ni}(\mathrm{dmit})_{2}\right]^{-}$molecules were $t_{1}=$ 14.52 and $t_{2}=-5.79 \mathrm{meV}$ within the chain, indicating the formation of weak dimers along the $a$ axis via side-by-side interactions. The one-dimensional chains interacted with each 50 other through sulfur-sulfur contacts along the $b$ axis. The shortest distance between the sulfur atoms along the $b$ axis was $4.183 \AA$. The interaction $t_{3}(1.48 \mathrm{meV})$ along the $b$ axis was about 10 times smaller than $t_{1}$ along the $a$ axis. Quasi-one-dimensional chains were formed in the anionic $\left[\mathrm{Ni}(\mathrm{dmit})_{2}\right]^{-}$layers.

55 
Table 2. Distances $(\AA)$ between selected atoms of the pyridazinium cation and oxygen atoms in the crown ether of crystal 1 at $93 \mathrm{~K}$.

\begin{tabular}{|c|c|c|c|c|c|}
\hline $\begin{array}{l}\mathrm{N}(1)- \\
\mathrm{O}(1)\end{array}$ & $2.892(3)$ & $\begin{array}{c}\mathrm{N}(1)- \\
\mathrm{O}(2)\end{array}$ & $3.203(5)$ & $\begin{array}{l}\mathrm{N}(1)- \\
\mathrm{O}(3)\end{array}$ & $3.953(4)$ \\
\hline $\begin{array}{l}\mathrm{N}(1)- \\
\mathrm{O}\left(1^{*}\right)\end{array}$ & $4.640(3)$ & $\begin{array}{l}\mathrm{N}(1)- \\
\mathrm{O}(2 *)\end{array}$ & $3.697(3)$ & $\begin{array}{l}\mathrm{N}(1)- \\
\mathrm{O}\left(3^{*}\right)\end{array}$ & $3.149(3)$ \\
\hline $\begin{array}{l}\mathrm{C}(1)- \\
\mathrm{O}(1)\end{array}$ & $3.933(3)$ & $\begin{array}{l}\mathrm{C}(1)- \\
\mathrm{O}(2)\end{array}$ & $3.417(4)$ & $\begin{array}{l}\mathrm{C}(1)- \\
\mathrm{O}(3)\end{array}$ & $3.051(5)$ \\
\hline $\begin{array}{l}\mathrm{C}(1)- \\
\mathrm{O}\left(1^{*}\right)\end{array}$ & $3.488(4)$ & $\begin{array}{l}\mathrm{C}(1)- \\
\mathrm{O}(2 *)\end{array}$ & $3.160(4)$ & $\begin{array}{l}\mathrm{C}(1)- \\
\mathrm{O}\left(3^{*}\right)\end{array}$ & $3.738(3)$ \\
\hline $\begin{array}{l}\mathrm{C}(2)- \\
\mathrm{O}(4)\end{array}$ & $3.223(4)$ & $\begin{array}{l}\mathrm{C}(2)- \\
\mathrm{O}(5)\end{array}$ & $3.485(3)$ & $\begin{array}{l}\mathrm{C}(2)- \\
\mathrm{O}(6)\end{array}$ & $4.430(3)$ \\
\hline $\begin{array}{l}\mathrm{C}(2)- \\
\mathrm{O}\left(4^{*}\right)\end{array}$ & $5.605(4)$ & $\begin{array}{l}\mathrm{C}(2)- \\
\mathrm{O}\left(5^{*}\right)\end{array}$ & $4.950(5)$ & $\begin{array}{l}\mathrm{C}(2)- \\
\mathrm{O}\left(6^{*}\right)\end{array}$ & $4.101(4)$ \\
\hline $\begin{array}{l}\mathrm{C}(3)- \\
\mathrm{O}(4)\end{array}$ & $2.915(5)$ & $\begin{array}{l}\mathrm{C}(3)- \\
\mathrm{O}(5)\end{array}$ & $3.174(5)$ & $\begin{array}{l}\mathrm{C}(3)- \\
\mathrm{O}(6)\end{array}$ & $3.705(3)$ \\
\hline $\begin{array}{l}\mathrm{C}(3)- \\
\mathrm{O}\left(4^{*}\right)\end{array}$ & $4.470(5)$ & $\begin{array}{l}\mathrm{C}(3)- \\
\mathrm{O}\left(5^{*}\right)\end{array}$ & $3.639(4)$ & $\begin{array}{l}\mathrm{C}(3)- \\
\mathrm{O}\left(6^{*}\right)\end{array}$ & $3.063(4)$ \\
\hline $\begin{array}{c}\mathrm{C}(4)- \\
\mathrm{O}(4)\end{array}$ & $4.151(8)$ & $\begin{array}{c}\mathrm{C}(4)- \\
\mathrm{O}(5)\end{array}$ & $3.836(9)$ & $\begin{array}{c}\mathrm{C}(4)- \\
\mathrm{O}(6)\end{array}$ & $3.191(6)$ \\
\hline $\begin{array}{l}\mathrm{C}(4)- \\
\mathrm{O}\left(4^{*}\right)\end{array}$ & $3.422(9)$ & $\begin{array}{l}\mathrm{C}(4)- \\
\mathrm{O}\left(5^{*}\right)\end{array}$ & $3.011(10)$ & $\begin{array}{l}\mathrm{C}(4)- \\
\mathrm{O}\left(6^{*}\right)\end{array}$ & $3.659(7)$ \\
\hline $\begin{array}{l}\mathrm{C}(5)- \\
\mathrm{O}(1)\end{array}$ & $3.554(7)$ & $\begin{array}{c}\mathrm{C}(5)- \\
\mathrm{O}(2)\end{array}$ & $4.282(8)$ & $\begin{array}{l}\mathrm{C}(5)- \\
\mathrm{O}(3)\end{array}$ & $5.128(7)$ \\
\hline $\begin{array}{l}\mathrm{C}(5)- \\
\mathrm{O}\left(1^{*}\right)\end{array}$ & $5.760(6)$ & $\begin{array}{l}\mathrm{C}(5)- \\
\mathrm{O}(2 *)\end{array}$ & $4.636(6)$ & $\begin{array}{l}\mathrm{C}(5)- \\
\mathrm{O}\left(3^{*}\right)\end{array}$ & $3.894(7)$ \\
\hline
\end{tabular}

* symmetry operation $(2-x,-y, 1-z)$

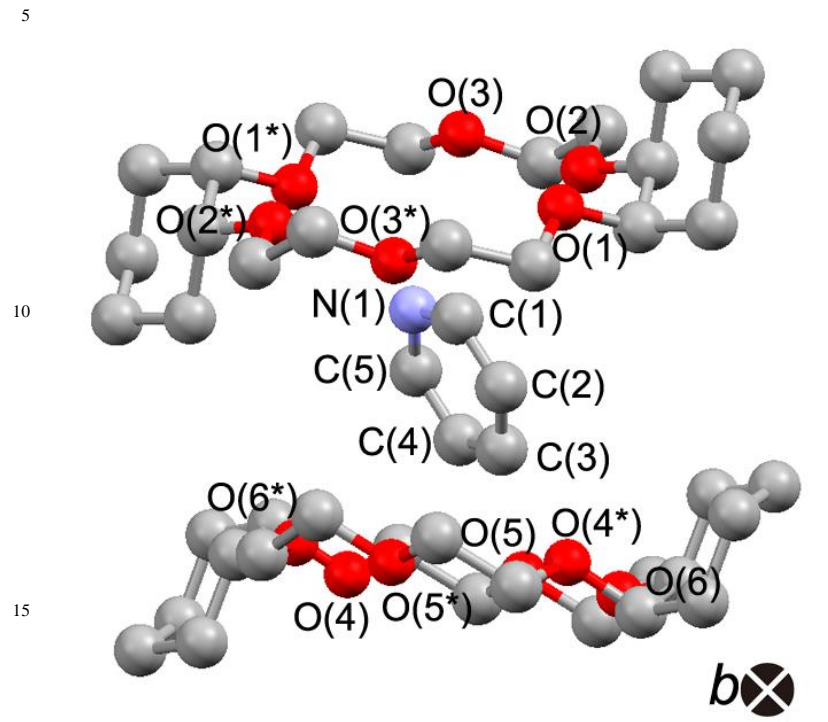

Fig. 2 Molecular conformation of the supramolecular cation in salt 1 along the $b$ axis at $93 \mathrm{~K}$. Hydrogen atoms are omitted for clarity.

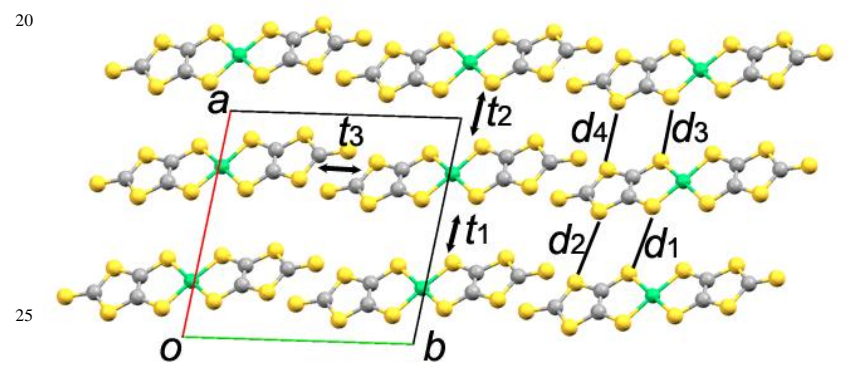

Fig. 3 (a) $\left[\mathrm{Ni}\left(\mathrm{dmit}_{2}\right]^{-}\right.$arrangement in crystal 1 viewed along the $c$ axis at $93 \mathrm{~K}$. Intermolecular interactions are indicated by $t_{1}, t_{2}$, and $t_{3}$. Sulfursulfur distances between the molecules are indicated by $d_{1}-d_{4}$.

\section{${ }_{30}$ Crystal Structure of $\left(\right.$ pyridazinium $\left.{ }^{+}\right)(\mathrm{DB}[18]$-crown- 6) $)_{2}\left[\mathrm{Ni}(\mathrm{dmit})_{2}\right]^{-}\left(\mathrm{H}_{2} \mathrm{O}\right)_{2}(2)$.}

Figure 4 shows the crystal structure of salt 2 at $93 \mathrm{~K}$. Two DB [18]-crown- 6 , one pyridazinium cation, one $\left[\mathrm{Ni}(\mathrm{dmit})_{2}\right]^{-}$, and two water molecules were crystallographically independent units. ${ }_{35}$ Supramolecular cations of DB[18]-crown-6 and pyridazinium formed layers on the $a(b+c)$ plane. Two water molecules were in the cationic layers and positioned on the outside of the supramolecular cation $\left(\right.$ pyridazinium $\left.{ }^{+}\right)\left(\mathrm{DB}[18]-\text { crown- }^{2}\right)_{2}$. No hydrogen bonding between the pyridazinium cation and the water 40 molecules was observed. $\left[\mathrm{Ni}(\mathrm{dmit})_{2}\right]^{-}$molecules existed in the voids of the layers, and one-dimensional chains were formed along the $a$ axis. No significant difference in either the crystal structure or the anisotropic thermal factors of the pyridazinium cation was observed between the structures at 93 and $300 \mathrm{~K}$ (see ${ }_{45}$ Supporting Information).

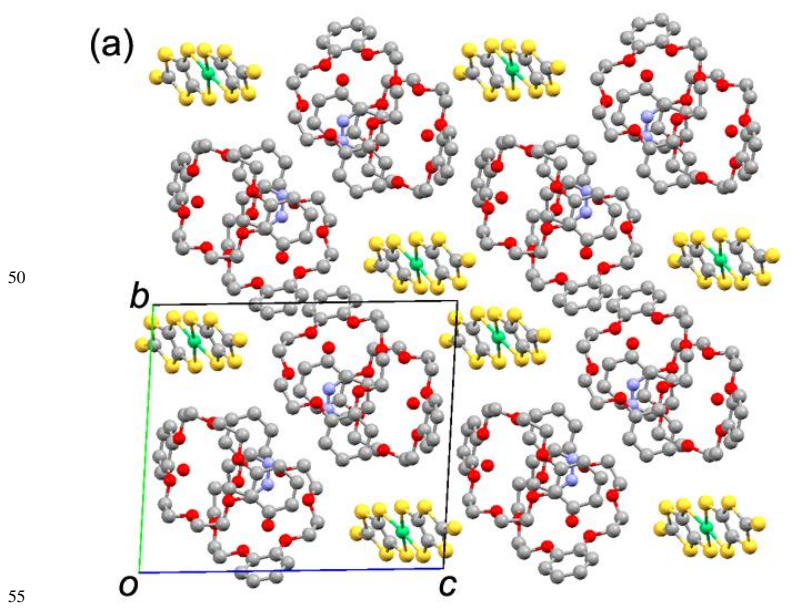

(b)

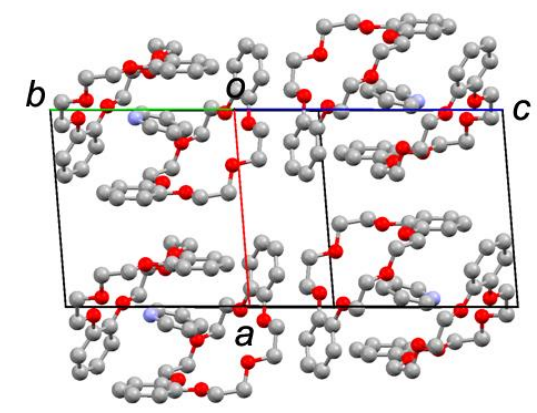

(c)

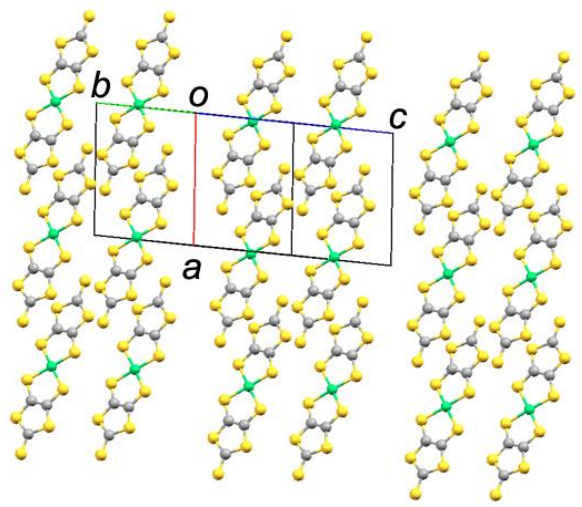

Fig. 4 (a) Crystal structure of salt 2 along the $a$ axis at 93 K. (b) Cationic layer in salt 2 parallel to the $a(b+c)$ plane. (c) $\left[\mathrm{Ni}(\mathrm{dmit})_{2}\right]^{-}$arrangement in salt 2 . Hydrogen atoms and water molecules have been omitted for clarity. 
(a)

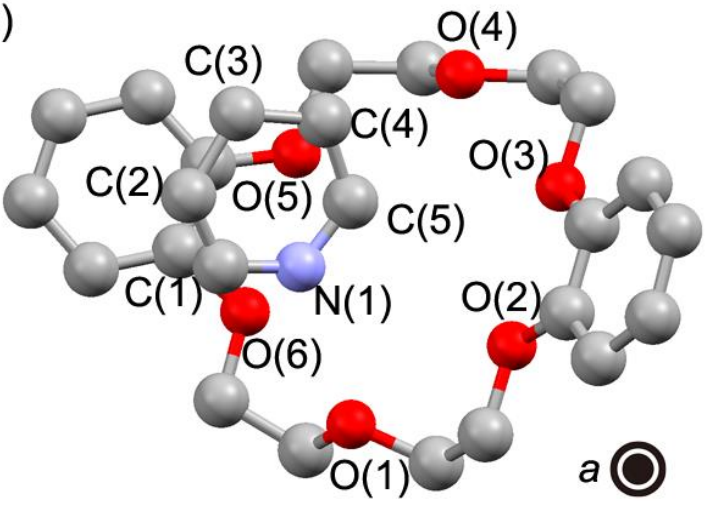

15

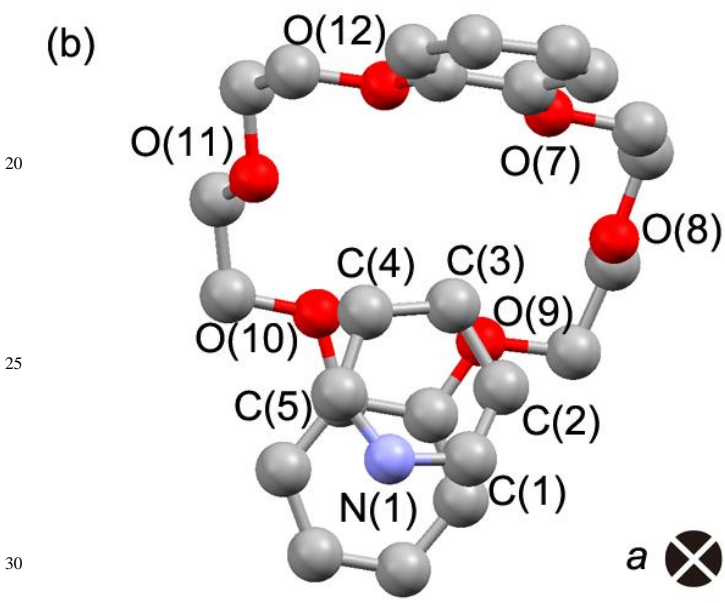

Fig. 5 Molecular arrangement of pyridazinium cation and DB[18]-crown-6 in crystal 2 along the $a$ axis.

Table 3. Distances $(\AA)$ between selected atoms on pyridazinium cation and oxygen atoms in the crown ether of crystal 2 at $93 \mathrm{~K}$.

\begin{tabular}{|c|c|c|c|c|c|}
\hline $\mathrm{N}(1)-\mathrm{O}(1)$ & $2.789(2)$ & $\begin{array}{c}\mathrm{N}(1)- \\
\mathrm{O}(2)\end{array}$ & $3.446(2)$ & $\begin{array}{c}\mathrm{N}(1)- \\
\mathrm{O}(3)\end{array}$ & $4.179(2)$ \\
\hline $\mathrm{N}(1)-\mathrm{O}(4)$ & $4.348(2)$ & $\begin{array}{c}\mathrm{N}(1)- \\
\mathrm{O}(5)\end{array}$ & $3.408(5)$ & $\begin{array}{c}\mathrm{N}(1)- \\
\mathrm{O}(6)\end{array}$ & $2.887(2)$ \\
\hline $\mathrm{C}(1)-\mathrm{O}(1)$ & $3.518(2)$ & $\begin{array}{c}\mathrm{C}(1)- \\
\mathrm{O}(2)\end{array}$ & $4.629(2)$ & $\mathrm{C}(1)-\mathrm{O}(3)$ & $5.396(2)$ \\
\hline $\mathrm{C}(1)-\mathrm{O}(4)$ & $5.318(2)$ & $\begin{array}{c}\mathrm{C}(1)- \\
\mathrm{O}(5)\end{array}$ & $3.964(2)$ & $\mathrm{C}(1)-\mathrm{O}(6)$ & $3.218(2)$ \\
\hline $\mathrm{C}(2)-\mathrm{O}(7)$ & $4.282(3)$ & $\begin{array}{c}\mathrm{C}(2)- \\
\mathrm{O}(8)\end{array}$ & $3.419(3)$ & $\mathrm{C}(2)-\mathrm{O}(9)$ & $3.232(3)$ \\
\hline $\begin{array}{l}\mathrm{C}(2)- \\
\mathrm{O}(10)\end{array}$ & $4.060(3)$ & $\begin{array}{l}\mathrm{C}(2)- \\
\mathrm{O}(11)\end{array}$ & $5.026(3)$ & $\begin{array}{l}\mathrm{C}(2)- \\
\mathrm{O}(12)\end{array}$ & $4.980(3)$ \\
\hline $\mathrm{C}(3)-\mathrm{O}(7)$ & $3.307(3)$ & $\begin{array}{c}\mathrm{C}(3)- \\
\mathrm{O}(8)\end{array}$ & $3.288(3)$ & $\mathrm{C}(3)-\mathrm{O}(9)$ & $3.261(3)$ \\
\hline $\begin{array}{l}\mathrm{C}(3)- \\
\mathrm{O}(10)\end{array}$ & $3.448(3)$ & $\begin{array}{l}\mathrm{C}(3)- \\
\mathrm{O}(11)\end{array}$ & $3.723(3)$ & $\begin{array}{l}\mathrm{C}(3)- \\
\mathrm{O}(12)\end{array}$ & $3.557(3)$ \\
\hline $\mathrm{C}(4)-\mathrm{O}(7)$ & $4.184(3)$ & $\begin{array}{c}\mathrm{C}(4)- \\
\mathrm{O}(8)\end{array}$ & $4.658(3)$ & $\mathrm{C}(4)-\mathrm{O}(9)$ & $4.140(2)$ \\
\hline $\begin{array}{l}\mathrm{C}(4)- \\
\mathrm{O}(10)\end{array}$ & $3.377(2)$ & $\begin{array}{l}\mathrm{C}(4)- \\
\mathrm{O}(11)\end{array}$ & $3.044(3)$ & $\begin{array}{l}\mathrm{C}(4)- \\
\mathrm{O}(12)\end{array}$ & $3.486(6)$ \\
\hline $\mathrm{C}(5)-\mathrm{O}(1)$ & $3.577(3)$ & $\begin{array}{c}\mathrm{C}(5)- \\
\mathrm{O}(2)\end{array}$ & $3.306(2)$ & $\mathrm{C}(5)-\mathrm{O}(3)$ & $3.226(2)$ \\
\hline $\mathrm{C}(5)-\mathrm{O}(4)$ & $3.224(2)$ & $\begin{array}{c}\mathrm{C}(5)- \\
\mathrm{O}(5)\end{array}$ & $3.034(2)$ & $\mathrm{C}(5)-\mathrm{O}(6)$ & $3.472(3)$ \\
\hline
\end{tabular}
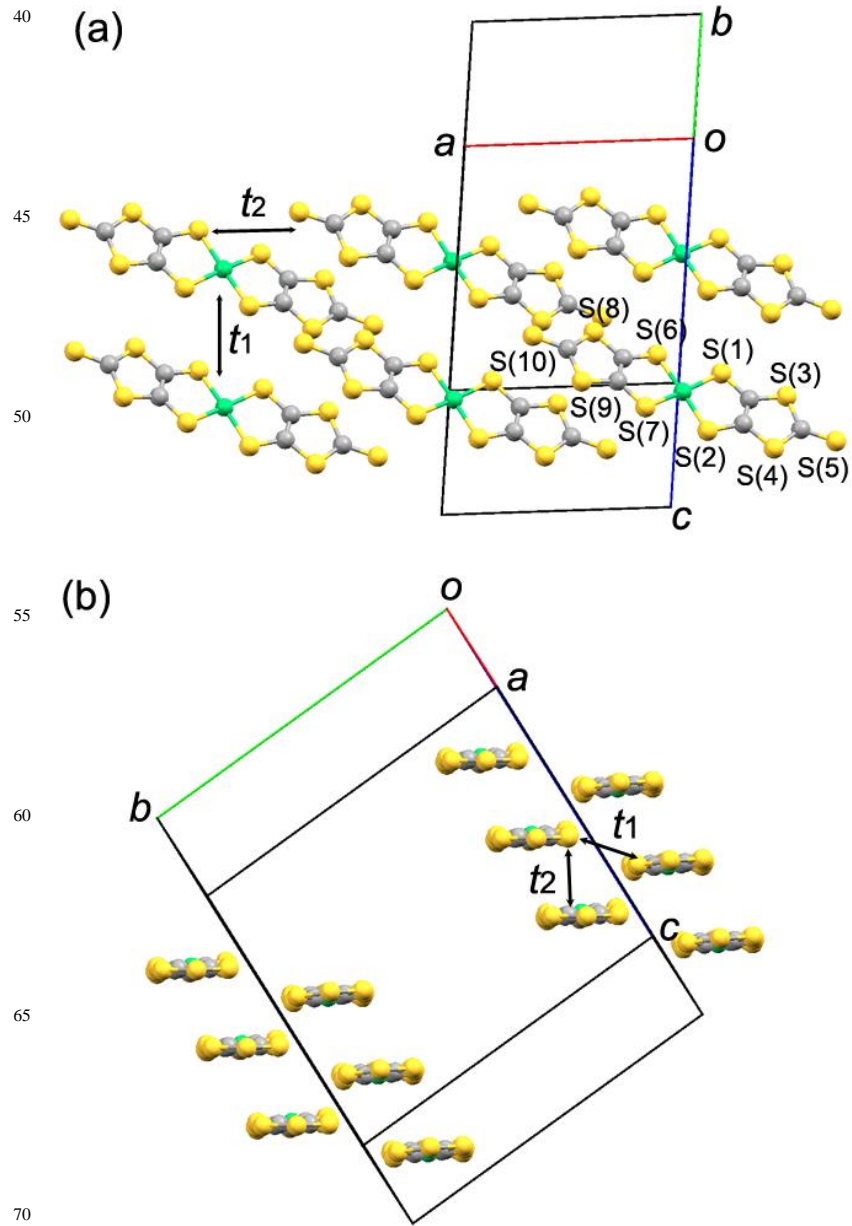

Fig. $6\left[\mathrm{Ni}(\mathrm{dmit})_{2}\right]^{-}$arrangement in crystal 2 along (a) the stacking direction and (b) the molecular long axis with atom labels

75

Figure 5 depicts the supramolecular structure of DB[18]-crown-6 and pyridazinium with atomic labels. DB[18]-crown-6 had a Vshaped conformation, which was also observed in the crystal of ( $m$-fluoroanilinium)(DB[18]-crown-6)[Ni(dmit $\left.)_{2}\right]^{-}$and $(m-$ 80 fluoroanilinium)(DB[18]-crown-6)[MnCr(oxalate $\left.)_{3}\right]^{-}$

$\left(\mathrm{CH}_{3} \mathrm{OH}\right)\left(\mathrm{CH}_{3} \mathrm{CN}\right){ }^{9}$ One pyridazinium molecule was sandwiched by two $\mathrm{DB}[18]$-crown-6 molecules. The shortest distance between the $\mathrm{N}(1)$ atom and oxygen atoms on $\mathrm{DB}[18]$-crown-6 was $2.789 \AA$ at $\mathrm{N}(1)-\mathrm{O}(1)$, forming hydrogen bonds. As in the 85 case of crystal $\mathbf{1}$, the position of other nitrogen atoms in the pyridazinium cation could not be determined and the neighboring atoms of $\mathrm{N}(1)$ in the pyridazinium cation were solved as carbon atoms. Although the shortest distances were at $\mathrm{C}(1)-\mathrm{O}(6)(3.217$ $\AA$ ) and $\mathrm{C}(5)-\mathrm{O}(5)(3.034 \AA$ ) , indicating weak hydrogen-bond ${ }_{90}$ formation at these positions, the nitrogen atom next to $\mathrm{N}(1)$ was expected to be disordered at the $\mathrm{C}(1)$ and $\mathrm{C}(5)$ positions in Figure 5. The distances between $\mathrm{C}(3)$ and the oxygen atoms $\mathrm{O}(7)-\mathrm{O}(12)$ of $\mathrm{DB}[18]$-crown-6 were in the range of 3.261-3.722 $\AA$, suggesting weak hydrogen-bond formation at these positions. ${ }^{18}$ ${ }_{95}$ Static disorder of the pyridazinium cation was observed in the solid. The larger steric hindrance around the pyridazinium cation 
in salt $\mathbf{2}$, compared with that of salt $\mathbf{1}$, caused by the phenyl rings of DB[18]-crown-6, would have restricted the flip-flop molecular motion in the solid state.

The $\left[\mathrm{Ni}(\mathrm{dmit})_{2}\right]^{-}$arrangement is shown in Figure 6. $\left[\mathrm{Ni}(\mathrm{dmit})_{2}\right]^{-}$ 5 formed one-dimensional chains parallel to the $a$ axis. The chains exist in the void of the supramolecular cations in salt 2 . Intermolecular interactions between $\left[\mathrm{Ni}(\mathrm{dmit})_{2}\right]^{-}$molecules through the $\mathrm{S} \cdots \mathrm{S}$ contacts shorter than the sum of the van der Waals radii $(<3.70 \AA)$ were observed at $S(8)-S\left(1^{\#}\right), S(6)-S\left(6^{\#}\right)$,

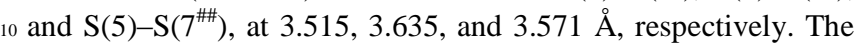
symmetry operations, \# and \#\#, were $(-x,-y, 1-z)$ and $(1+x, y, z)$. Figure 6(b) exhibits a stacking motif of the $\left[\mathrm{Ni}(\mathrm{dmit})_{2}\right]^{-}$ molecules in crystal $\mathbf{2}$. Two chains that formed along the $c$ axis interacted with each other through side-by-side $\mathrm{S} \cdots \mathrm{S}$ interactions.

15 The transfer integrals between the LUMOs of the $\left[\mathrm{Ni}(\mathrm{dmit})_{2}\right]^{-}$ molecules, $t_{1}$ and $t_{2}$, were calculated by the extended Hückel method. The interaction $t_{2}(78.9 \mathrm{meV})$ was about seven times larger than the interaction $t_{1}(-11.7 \mathrm{meV})$, showing the quasi-onedimensional nature of the chains along the $c$ axis direction.

\section{${ }_{20}$ Potential energy calculation.}
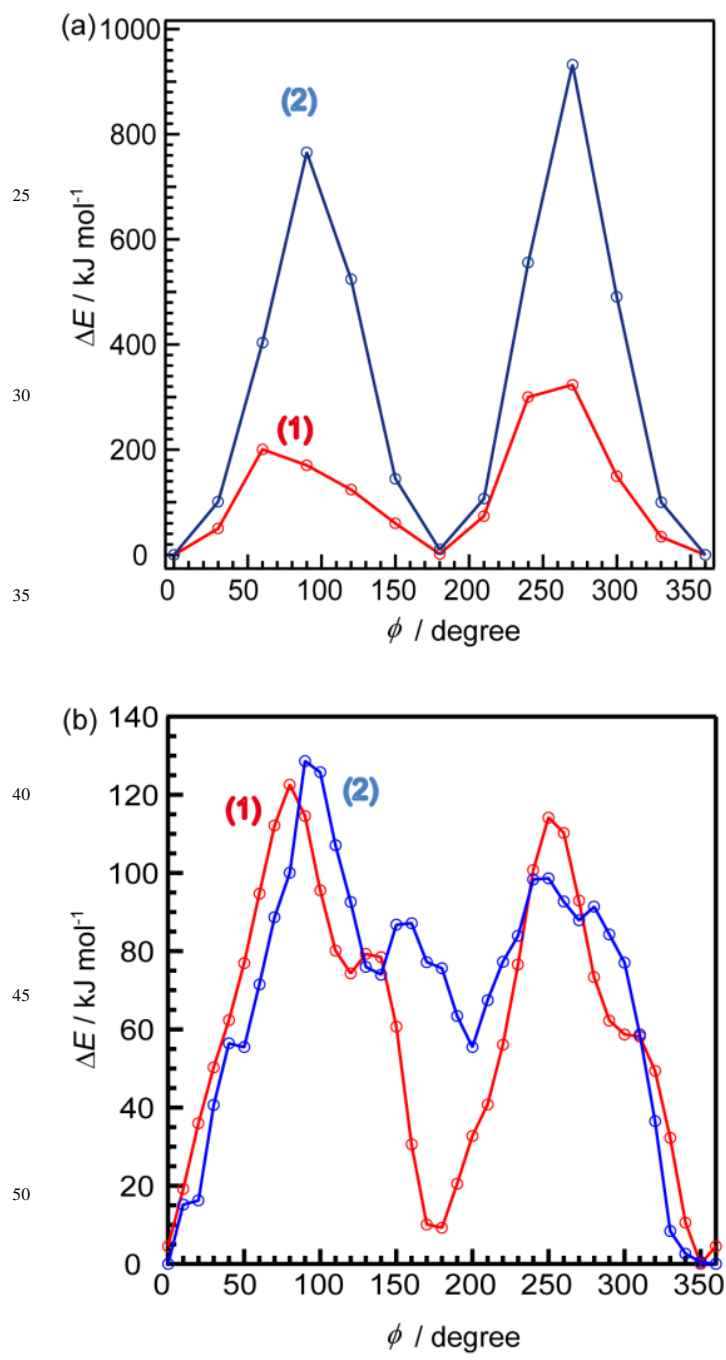

${ }_{55}$ Fig. 7 Potential energy curves for (a) the flip-flop motion and (b) the in-plane motion of the pyridazinium cations in the supramolecular cations of salts $\mathbf{1}$ and $\mathbf{2}$. Solid lines are a visual guide.
To evaluate the molecular motions of the supramolecular cations 60 in crystals $\mathbf{1}$ and $\mathbf{2}$, the potential energy barriers for the molecular rotations of the pyridazinium cations were calculated by a restricted Hartree-Fock (RHF) method. Figure S3 shows model structures of the supramolecular cations in salts $\mathbf{1}$ and $\mathbf{2}$ for the calculation. These structures differed from the real stoichiometry 65 of the salts. The atomic coordinates based on the X-ray crystal structure analyses of the salts at $93 \mathrm{~K}$ were used in the calculation. Hydrogen atoms on the pyridazinium cations were placed at the $\mathrm{N}(1)$ and $\mathrm{C}(1)-\mathrm{C}(4)$ positions. The nearest neighbors of $\mathrm{N}(1)$ were $C(1)$ and $C(5)$. X-ray crystallographic analysis suggested 70 orientational disorder of the nitrogen atom. In these calculations, protons were not placed at $\mathrm{C}(5)$ next to $\mathrm{N}(1)$. The rotations were performed in $30^{\circ}$ steps around the $\mathrm{N}(1)-\mathrm{C}(3)$ axis. The relative energies were calculated using fixed atomic coordinates. Thus, the results of the calculations overestimated the actual energy 75 barriers. Figure 7(a) shows the potential energy curves for crystals 1 and 2. Double-minimum potential curves for the flipflop motions of pyridazinium cations were obtained. For $\mathbf{1}$, the local maximum values were observed to be 210 and $310 \mathrm{~kJ} \mathrm{~mol}^{-1}$ at 90 and $270^{\circ}$, respectively. The potential curve is asymmetric 80 because of the asymmetric configurations of $\mathrm{DCH}[18]$-crown- 6 molecules in the vertical direction of the rotation axis. The energy barriers were larger than the thermal energy at room temperature $\left(2.5 \mathrm{~kJ} \mathrm{~mol}^{-1}\right.$ ) because the thermal fluctuations and relaxation of the atoms were disregarded. However, flip-flop motion was 85 observed in ( $m$-fluoroanilinium)(DB[18]-crown-6)[Ni(dmit $)_{2}$ ], where the energy barrier was calculated to be $250 \mathrm{~kJ} \mathrm{~mol}^{-1}$ by the same calculation method. ${ }^{9-11}$ Thus, the flip-flop motion of the pyridazinium cations in salt $\mathbf{1}$ should be possible around room temperature. In the case of crystal 2 , maxima of $800 \mathrm{~kJ} \mathrm{~mol}^{-1}$ and $90900 \mathrm{~kJ} \mathrm{~mol}^{-1}$ occurring at 90 and $270^{\circ}$, respectively, were observed; these were three times larger than those of salt $\mathbf{1}$. The pyridazinium cation in salt $\mathbf{2}$ is surrounded by rigid aromatic moieties of DB[18]-crown-6 molecules suppressing the flip-flop motion of the pyridazinium cation. For salts $\mathbf{1}$ and $\mathbf{2}$, the 95 potentials for the in-plane rotation of the pyridazinium cation were also calculated. The model structure for the calculation was the same as for the calculation of flip-flop motion. Rotations were performed in $10^{\circ}$ steps. In this calculation, the effects of the hydrogen bonding between the nitrogen and oxygen atoms were 100 ignored because of limited computational resources. Figure 7(b) shows the potential energy curve for in-plane rotation of the pyridazinium cation in salts $\mathbf{1}$ and $\mathbf{2}$. The energy curve of salt $\mathbf{1}$ showed a double minimum with a small energy barrier (ca. 120 $\mathrm{kJ} \mathrm{mol}^{-1}$ ). The general hydrogen bond $\mathrm{N}-\mathrm{H}^{+} \sim \mathrm{O}$ has a binding 105 energy in the range $5-30 \mathrm{~kJ} \mathrm{~mol}^{-1}$, which is slightly larger than the thermal energy at room temperature. The small energy barrier suggests in-plane rotation of the pyridazinium cation and agrees with the X-ray crystallographic analysis of salt $\mathbf{1}$. The energy curve of salt 2 exhibited a stable state at $0^{\circ}$ and a metastable state 110 at around $180^{\circ}$ with the same energy barrier as that of salt $\mathbf{1}$ (ca. $115 \mathrm{~kJ} \mathrm{~mol}^{-1}$ ), indicating that in-plane rotation of the pyridazinium cation may be allowed at room temperature. The $180^{\circ}$ rotation position is a metastable state according to the potential calculation, which coincides with the results of the $\mathrm{X}$ 115 ray crystallographic analysis, where nitrogen atoms may not exist at the $\mathrm{C}(3)$ position, judging from the hydrogen-bond distance. 
Direct evidence of in-plane rotation has not yet been obtained. Further experiments, such as the measurement of the temperature-dependent dielectric response and solid-state NMR, are required to confirm in-plane rotation in salt 2.

\section{${ }_{5}$ Magnetic Properties.}

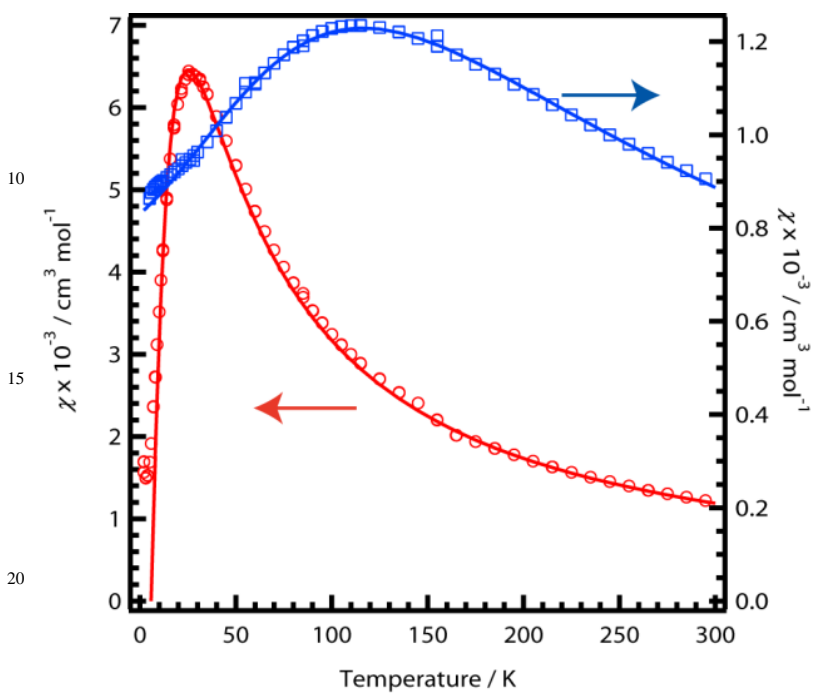

Fig. 8 Temperature dependence of magnetic susceptibility of salts 251 (red $\circ$ ) and 2 (blue $\square$ ). Red and blue solid lines indicate the fitting lines based on alternating antiferromagnetic Heisenberg chains and the Bonner-Fisher model for salts $\mathbf{1}$ and $\mathbf{2}$, respectively.

30 The temperature dependence of molar magnetic susceptibility $\left(\chi_{\mathrm{mol}}\right)$ per $\left[\mathrm{Ni}(\mathrm{dmit})_{2}\right]^{-}$anion was directly affected by the anion arrangements in the crystals. Figure 8 plots $\chi_{\text {mol }}$ versus $T$ for salts 1 and 2. $\chi_{\text {mol }}$ versus $T$ behaviour of salt 1 clearly exhibited antiferromagnetic interactions between the $\left[\mathrm{Ni}(\mathrm{dmit})_{2}\right]^{-}$anions.

35 The $\chi_{\text {mol }}$ versus $T$ plots around room temperature showed CurieWeiss behaviour. Further lowering of the temperature resulted in a broad $\chi_{\text {mol }}$ maximum around $30 \mathrm{~K}$, and a rapid decrease in $\chi_{\text {mol }}$ was observed below $30 \mathrm{~K}$. This kind of temperature dependence has been typically observed in one-dimensional antiferromagnetic

${ }_{40}$ Heisenberg chains or singlet-triplet $(\mathrm{S}-\mathrm{T})$ dimers. The magnitude of the interchain transfer integrals $\left(t_{1}=14.52\right.$ and $\left.t_{2}=-5.79 \mathrm{meV}\right)$ of salt 1 suggested the formation of an alternating onedimensional chain or isolate lateral $\left[\mathrm{Ni}(\mathrm{dmit})_{2}\right]^{-}$dimer, which depends on the ratio of intra- $\left(J_{1}\right)$ to interdimer $\left(J_{2}\right)$ magnetic 45 exchange energy. Assuming the relationship $|J| \sim t^{2}$, the $J_{1} / J_{2}$ ratio based on the transfer integrals of salt 1 was about 6.3 (Intradimer $J_{1}>$ >Interdimer $J_{2}$ ). The alternating antiferromagnetic Heisenberg chain model was applied to explain the $\chi_{\text {mol }}$ versus $T$ behaviour of salt $\mathbf{1},{ }^{19}$ which almost reproduced the temperature-dependent 50 magnetic behaviour above $11 \mathrm{~K}$ using the fitting parameters of intradimer $J_{1}=-17.2 \mathrm{~K}$ and interdimer $J_{2}=9.0 \mathrm{~K}$. The $J_{1} / J_{2}$ ratio of $\sim 2$ was almost the same as the ratio from the molecular orbital calculation. The $\mathrm{S}-\mathrm{T}$ thermal excitation model was also used for the fitting of the $\chi_{\text {mol }}$ versus $T$ behaviour of salt 1 . However, 55 deviations from the theoretical model were observed above $17 \mathrm{~K}$. The $\chi_{\text {mol }}$ versus $T$ behaviour of salt $\mathbf{1}$ was not in good agreement with this theoretical model. From the crystal structure, theoretical calculations, and fitting results of the magnetic susceptibility, the magnetic property of salt $\mathbf{1}$ was explained by the alternating 60 antiferromagnetic Heisenberg chain. $\chi_{\text {mol }}$ versus $T$ behaviour of salt 2 also indicated antiferromagnetic interactions between the $\left[\mathrm{Ni}(\mathrm{dmit})_{2}\right]^{-}$anions. $\chi_{\mathrm{mol}}$ around room temperature gradually increased as $T$ decreased from 300 to $100 \mathrm{~K}$. Around $100 \mathrm{~K}$, a broad $\chi_{\text {mol }}$ maximum was observed, with moderate decreases ${ }_{65}$ below $100 \mathrm{~K}$. This kind of temperature dependence has been typically observed in one-dimensional antiferromagnetic Heisenberg chains. The magnitude of the intrachain transfer integral $\left(t_{2}=78.9 \mathrm{meV}\right)$ of salt 2 suggested the formation of a uniform one-dimensional chain formed by $\left[\mathrm{Ni}(\mathrm{dmit})_{2}\right]^{-}$molecules. 70 A uniform antiferromagnetic Heisenberg chain model, i.e., Bonner-Fisher model, was applied to explain the $\chi_{\text {mol }}$ versus $T$ behaviour of salt $2,{ }^{20}$ which almost reproduced the temperaturedependent magnetic behaviour above $40 \mathrm{~K}$ using the fitting parameter $J_{1}=-89.9 \mathrm{~K}$.

\section{${ }_{75}$ Conclusion}

Hydrogen-bonding molecular assemblies between pyridazinium and crown ethers of DCH[18]-crown-6 and DB[18]-crown-6 formed in $\left[\mathrm{Ni}(\mathrm{dmit})_{2}\right]^{-}$salts. Molecular rotators with two different types of rotation, $180^{\circ}$ flip-flop motion and in-plane rotation, 80 were constructed in $\left(\right.$ pyridazinium $\left.^{+}\right)(\mathrm{DCH}[18]$-crown6) $\left[\mathrm{Ni}(\mathrm{dmit})_{2}\right]^{-}$(1). The bulky DCH[18]-crown-6 served to keep crystalline space for rotations, and the use of a small pyridazinium molecule rather than substituted anilinium derivatives proved effective for the construction of rotators in the

85 solid state. A quasi-one-dimensional chain of $\left[\mathrm{Ni}(\mathrm{dmit})_{2}\right]^{-}$with alternating interactions through the sulfur-sulfur contacts was observed in $\left(\right.$ pyridazinium $\left.^{+}\right)(\mathrm{DCH}[18] \text {-crown-6)[Ni(dmit) })_{2}^{-}$(salt 1), which exhibited antiferromagnetic behavior. Uniform onedimensional antiferromagnetic behaviour was observed in ${ }_{90}\left(\right.$ pyridazinium $\left.^{+}\right)\left(\mathrm{DB}[18]\right.$-crown-6) ${ }_{2}\left[\mathrm{Ni}(\mathrm{dmit})_{2}\right]^{-}(\mathbf{2})$, which obeyed the Bonner-Fisher model. Crystallographic analysis and potential energy calculations of (pyridazinium $\left.{ }^{+}\right)(\mathrm{DCH}[18]$-crown6) $\left[\mathrm{Ni}(\mathrm{dmit})_{2}\right]^{-}\left(\mathrm{H}_{2} \mathrm{O}\right)_{2}$ indicated the presence of not only flip-flop motion but also in-plane rotation of the pyridazinium cation in a 95 magnetic solid. To investigate further details of the molecular motions, the temperature-dependent dielectric response and solidstate NMR measurements are now in progress.

\section{Notes and references}

${ }^{a}$ Graduate School of Environmental Science, Hokkaido University, 100 Sapporo 060-0812, Japan. Fax: +81-11-706-9420; Tel: +81-11-7069419; E-mail: zunqi85@es.hokudai.ac.jp (L.Z.)

${ }^{b}$ Research Institute for Electronic Science, Hokkaido University, Sapporo 001-0020, Japan. Fax: +81-11-706-9420; Tel: +81-11-706-9455; Email: kkubo@es.hokudai.ac.jp (K.K)

105 c Institute of Multidisciplinary Research for Advanced Materials, Tohoku University, Sendai 980-8577, Japan. Fax: +81-22-217-5655; Tel: +8122-217-5653; E-mail: akuta@tagen.tohoku.ac.jp (T.A.)

$\dagger$ Electronic Supplementary Information (ESI) available: thermogravimetric analyses, infrared spectra, crystallographic analyses, 110 model structures for the RHF calculation, and CIF files of crystals $\mathbf{1}$ and $\mathbf{2}$. See DOI: 10.1039/b000000x/ CCDC numbers: 907570 - 907573.

1 L. F. Lindoy, I. M. Atkinson, Self-Assembly in Supramolecular Systems; Stoddart, J. F., Ed.; RSC: Cambridge, 2000; Molecular Switches; B. L. Feringa, Ed.; Wiley-VCH: Weinheim, Germany, 115 2001; Molecular Machines and Motors; J.-P. Sauvage, Ed.; Springer: Berlin, 2001; Molecular Devices and Machines; V. Balzani, M. 
Venturi, A. Credi, Eds.; Wiley-VCH: Weinheim, Germany, 2003; C. Bustamante, D. Keller, G. Oster, Acc. Chem. Res. 2001, 34, 412-420.

2 L. Stryer, Biochemistry, Freeman, New York, 1995.

3 G. S. Kottas, L. I. Clarke, D. Horinek, J. Michl, Chem. Rev. 2005, 105, 1281; E. R. Kay, D. A. Leigh, F. Zerbetto, Angew. Chem. Int. Ed., 2007, 46, 72.

4 D. A. Leigh, J. K. Y. Wong, F. Dehez, F. Zerbetto, Nature, 2003, 424, 174.

5 S. Hiraoka, K. Harano, T. Tanaka, M. Shiro, M. Shionoya, Angew.

10 Chem. Int. Ed., 2003, 42, 5182; S. Hiraoka, K. Hirata, M. Shionoya, Angew. Chem. Int. Ed., 2004, 43, 3814; S. Hiraoka, M. Shiro, M. Shionoya, J. Am. Chem. Soc., 2004, 126, 1214; S. Hiraoka, Y. Hisanaga, M. Shiro, M. Shionoya, Angew. Chem. Int. Ed., 2010, 49, 1669.

156 T. Muraoka, K. Kinbaraand, T. Aida, Nature, 2006, 440, 512; T. Muraoka, K. Kinbara, Y. Kobayashi, T. Aida, J. Am. Chem. Soc., 2003, 125, 5612.

7 T. R. Kelly, H. De Silva, R. A. Silva, Nature, 1999, 401, 150.

8 T. -A. V. Khuong, J. E. Nuñez, C. E. Godinez, M. A. GARCIA-

20 GARIBAY, Acc. Chem. Res., 2006, 39, 413; Z. Dominguez, H. Dang, M. Jane Strouse, M. A. Garcia-Garibay, J. Am. Chem. Soc., 2002, 124, 2398; S. D. Karlen, C. E. Godinez, M. A. Garcia-Garibay, Org. Lett., 2006, 8, 3417; T.-A. V. Khuong, H. Dang, P. D. Jarowski, E. F. Maverick, M. A. Garcia-Garibay, J. Am. Chem. Soc., 2007, 129, 839.

259 T. Akutagawa, D. Sato, Q. Ye, S. Noro, T. Nakamura, Dalton Trans., 2010, 39, 2191; T. Endo, T. Akutagawa, S. Noro, T. Nakamura, Dalton Trans., 2011, 40, 1491.

10 S. Nishihara, T. Akutagawa, D. Sato, S. Takeda, S. Noro, T. Nakamura, Chem. Asian J., 2007, 2, 1083; S. Nishihara, T.

30 Akutagawa, T. Hasegawa, S. Fujiyama, T. Nakamura, J. Solid State Chem, 2002, 168, 661; S. Nishihara, T. Akutagawa, T. Hasegawa, T. Nakamura, Chem. Commun., 2002, 408.

11 T. Akutagawa, H. Koshinaka, D. Sato, S. Takeda, S. Noro, H. Takahashi, R. Kumai, Y. Tokura, T. Nakamura, Nat. Mater., 2009, 8, 342.

12 T.Akutagawa, H. Koshinaka, Q. Ye, S. Noro, J. Kawamata, H. Yamaki, T. Nakamura, Chem. Asian J., 2010, 5, 520; T. Akutagawa, T. Nakamura, Dalton Trans., 2008, 6335; T. Akutagawa, K. Matsuura, A. Hashimoto, T. Nakamura, Inrog. Chem., 2005, 44, 4454; T. Akutagawa, D. Sato, H. Koshinaka, M. Aonuma, S. Noro, S. Takeda, T. Nakamura, Inrog. Chem., 2008, 47, 5951; T. Akutagawa, K. Matsuura, S. Nishihara, S. Noro, T. Nakamura, Eur. J. Inorg. Chem. 2005, 3271; S. Nishihara, X. M. Ren, T. Akutagawa, T. Nakamura, Polyhedron, 2005, 24, 2844; T. Akutagawa, T. Hasegawa,

45 T. Nakamura, T. Inabe, J. Am. Chem. Soc., 2002, 124, 8903; T. Akutagawa, D. Endo, H. Imai, S. Noro, L. Cronin, T. Nakamura, Inorg. Chem., 2006, 45, 8628; T. Akutagawa, D. Endo, S. Noro, L. Cronin, T. Nalamura, Coord. Chem. Rev., 2007, 251, 2547; Q. Ye, T. Akutagawa, T. Endo, S. Noro, T. Nakamura, R. Xiong, Inorg Chem. 50 2010, 49, 8591; Q. Ye, T. Akutagawa, S. Noro, T. Nakamura, R. Xiong, Crystal Growth and Design 2010, 10, 4856.

13 M. Lämsä, J. Huuskonen, K. Rissanen, J. Pursiainen, Chem. Eur. J., 1998, 4, 84; M. Meot-Ner, J. Am. Chem. Soc., 1983, 105, 4912.

14 G. Steimecke, H. Sieler, R. Kirmse, E. Hoyer, Phosphor Sulfur, 1979, $55 \quad 7,49$.

15 M. C. Burla, R. Caliandro, M. Camalli, B. Carrozzini, G. L. Cascarano, L. De Caro, C. Giacovazzo, G. Polidori, R. Spagna, J. Appl. Crystallogr., 2005, 38, 381; M. Sheldrick, G. SHELXL-97 Program of the refinement of crystal structures, University of

60 Göttingen, Germany, 1997; C. Kabuto, S. Akine, T. Nemoto, E. Kwon, J. Cryst. Soc. Jpn., 2009, 51, 218.

16 M. J. Frisch, G. W. Trucks, H. B. Schlegel, G. E. Scuseria, M. A. Robb, J. R. Cheeseman, J. A. Jr. Montgomery, T. Vreven, K. N. Kudin, J. C. Burant, J. M. Millam, S. S. Iyengar, J. Tomasi, V. 65 Barone, B. Mennucci, M. Cossi, G. Scalmani, N. Rega, G. A. Petersson, H. Nakatsuji, M. Hada, M. Ehara, K. Toyota, R. Fukuda, J. Hasegawa, M. Ishida, T. Nakajima, Y. Honda, O. Kitao, H. Nakai, M. Klene, X. Li, J. E. Knox, H. P. Hratchian, J. B. Cross, V. Bakken, C. Adamo, J. Jaramillo, R. Gomperts, R. E. Stratmann, O. Yazyev, A. J. Austin, R. Cammi, C. Pomelli, J. W. Ochterski, P. Y. Ayala, K. Morokuma, G. A. Voth, P. Salvador, J. J. Dannenberg, V. G.
Zakrzewski, S. Dapprich, A. D. Daniels, M. C. Strain, O. Farkas, D. K. Malick, A. D. Rabuck, K. Raghavachari, J. B. Foresman, J. V. Ortiz, Q. Cui, A. G. Baboul, S. Clifford, J. Cioslowski, B. B. Stefanov, G. Liu, A. Liashenko, P. Piskorz, I. Komaromi, R. L. Martin, D. J. Fox, T. Keith, M. A. Al-Laham, C. Y. Peng, A. Nanayakkara, M. Challacombe, P. M. W. Gill, B. Johnson, W. Chen, M. W. Wong, C. Gonzalez, J. A. Pople, Gaussian 03, Revision C.02, Gaussian, Inc., Wallingford, CT, 2004.

8017 T. A. Albright, P. Hofmann, R. Hoffmann, J. Am. Chem. Soc., 1977, 99, 7546; K. A. Joergensen, R. A. Wheeler, R. Hoffmann, J. Am. Chem. Soc., 1987, 109, 3240; D. A. Keszler, R. Hoffmann, J. Am. Chem. Soc., 1987, 109, 118.

18 J. C. Bonner, H. W. J. Bröte, J. W. Bray, I. S. Jacobs, J. Appl. Phys., $1979, \mathbf{5 0}, 1810$.

19 J. C. Bonner, M. E. Fisher, Phys. Rev. A 1964, 135, 640; S. Eggert, I. Affleck, M. Takahashi, Phys. Rev. Lett., 1994, 73, 332; M. Shiroishi, M. Takahashi, Phys. Rev. Lett., 2002, 89, 117201. 